\title{
Pandemia y derechos reproductivos. Respuestas y desventajas
}

\section{Pandemic and Reproductive Rights. Answers and Disadvantages}

\section{Valeria Venticinque}

Valeria Venticinque es docente e investigadora de la Escuela de Ciencia Política, Facultad de Ciencia Política y Relaciones Internacionales, Universidad Nacional de Rosario, Argentina.

E-mail: valeriaventicinque@yahoo.com.ar

\section{resumen}

Nuestra mirada buscará realizar un análisis, desde los estudios de género y feministas, de los acontecimientos que se desarrollaron en Argentina a partir del surgimiento de la pandemia y el establecimiento de la cuarentena. Así, nos proponemos observar las formas en que el Covid-19 afectó el ejercicio de los derechos (no) reproductivos de las personas gestantes, en la búsqueda de analizar las situaciones que se desarrollaron en el sub-sector de la salud pública.

\section{summary}

Our gaze will seek to carry out an analysis from the studies of gender and feminists of the events that took place in Argentina from the emergence of the pandemic and the establishment of quarantine. Thus, we intend to observe the ways in which Covid-19 affected the exercise of the (non) reproductive rights of pregnant persons, seeking to analyze the situations that developed in the sub-sector of public health.

\section{palabras clave}

Covid-19 / derechos reproductivos / efectores públicos

\section{keywords}

Covid-19 / reproductive rights / public effectors 


\section{Introducción}

El día 9 de marzo, el Ministerio de Salud de la Nación confirmó los dos primeros casos positivos de coronavirus en el Chaco. Fue la segunda provincia en importarlo $\mathrm{y}$, desde ese momento hasta el día de la fecha, el virus nunca pudo detenerse en Argentina. ${ }^{1}$

La irrupción de la pandemia en territorio argentino tuvo lugar en el marco de la transición de la administración nacional, aunque, abruptamente, un desbarajuste llamó a la contingencia y, a partir de ese momento, mucho responderá a la improvisación. Como señala Karina Ramacciotti (2020), la emergencia de los primeros casos de Covid-19 en la Argentina condujo a un conjunto de situaciones que nos interpela a nivel colectivo, y las autoridades nos instan a cumplir con un puñado de prácticas, tales como extremar la higiene de manos y la limpieza de nuestros hogares, atender los cuidados hacia las personas cercanas que son vulnerables y mantener un estricto aislamiento social. Todo ello se dio en pos de disminuir las posibilidades de propagación de esta enfermedad infecciosa. En este marco, el presente escrito ofrece una breve descripción y análisis en torno a las disposiciones tomadas desde las gestiones nacionales y provinciales - con el foco puesto en la provincia de Santa Fe- ante los problemas emergentes de la pandemia en relación con los derechos (no) reproductivos (en adelante DD.RR). Nos dedicaremos específicamente a lxs pacientes de efectores públicos que, por su posición económica-social, no pueden acceder a otro tipo de prestaciones.

\section{EI SARS-CoV-2 (Covid-19) y la nueva administración nacional}

La opinión pública observa la flamante gestión de Fernández-Fernández como un peronismo un tanto ligero, con el techo impuesto por la herencia neoliberal y los conflictos provenientes del contexto pandémico. Hasta la irrupción del Covid19 y su veloz expansión en tanto pandemia, el Gobierno construía a partir de algunos anuncios institucionales que colaborarían para pensar los derechos por el camino de la perspectiva de género y diversidades. En este sentido, el año 2019 quedó grabado en la historia nacional por el surgimiento del Ministerio de las Mujeres, Géneros y Diversidad, que vino a cumplir con las promesas de la campaña electoral de jerarquizar el Instituto Nacional de las Mujeres. Ya desde las primeras semanas del mes de marzo se podía vislumbrar que la pandemia adoptaría formas clasistas y sexistas, e invadiría violentamente las vidas de aquellxs que viven la vulneración de sus derechos como parte de su cotidianeidad.

En relación con los DD.RR., la seguridad a la hora de parir es fundamental. Sin embargo, las mujeres argentinas se encontraron durante la cuarentena con incertidumbre y miles de respuestas confusas. En este sentido, las personas gestantes debieron asumir el derecho a denunciar el incumplimiento de la norma que las protege, la Ley de Parto Humanizado. Así, las personas afectadas podían realizar el correspondiente reclamo en la Comisión Nacional Coordinadora de Acciones para la elaboración de sanciones de la Violencia de Género (en adelante CONSAVIG), o contactarse con el INADI o la Defensoría del Pueblo. 
Durante el período marzo-agosto, a nivel nacional, con la cuarentena obligatoria establecida, los embarazos y los partos debieron ser regulados mediante protocolos especiales. ${ }^{2}$ En relación con las personas gestantes con sospecha o con confirmación de Covid-19, las recomendaciones fueron similares a las indicaciones realizadas para las personas mayores de 60 años. Más allá de las medidas de restricción, se permitió la visita de una persona elegida que no se encontrara dentro de ningún grupo de riesgo y que tomara todos los recaudos pertinentes. Además, se debía tener recaudos en caso de partos prematuros, y tanto las personas sospechadas de Covid-19, como aquellas que poseían efectivamente la infección, si se consideraba que su estado era intermedio o grave, debía procederse a internarlas.

El Presidente, a su vez, anunció la licencia laboral para embarazadas; se las incluyó en los grupos de riesgo también en este punto. Por otra parte, se realizó una serie de recomendaciones para las personas gestantes con asesoramiento de la Organización Mundial de la Salud (en adelante OMS), la cual expresó que el acompañamiento es la forma de lograr un parto seguro, incluso en el marco de la pandemia.

En síntesis, todas las personas gestantes, incluidas aquellas con confirmación de Covid-19, las aisladas y las sospechadas de infección, debían permanecer en cuarentena, pero siempre con el resguardo de los debidos cuidados que la situación ameritaba.

En el momento del parto, el protocolo establecía que se debía aplicar el criterio del obstetra, y siempre condicionado a la salud materna. Se recomendaba el parto natural, a no ser alguna contraindicación para lxs pacientes infectadas con Covid19. Así, la salud y la vida de las personas gestantes quedaban bajo la decisión de los equipos de salud, que, en última instancia, respondían a los sistemas gubernamentales, los cuales entendían y entienden que poseen la responsabilidad de la protección, aunque muchas de estas prácticas de cuidados terminan por profundizar la vulnerabilidad (Biglia y San Martín, 2007: 30).

De esta forma, las realidades se tornan complejas, y el alcance de las medidas no siempre logra deconstruir las insoportables desigualdades que deterioran la forma de ser y pensarse ciudadanxs. ${ }^{34}$ Como señala Soledad Deza (2014), la vulnerabilidad de la mujer pobre tiene la posibilidad de cobrar dimensiones desproporcionadas cuando de autonomía sexual y reproductiva se trata. Esto dificulta un punto de partida justo y genera desigualdades que signan sus vidas con experiencias sexuales deprotegidas (Deza, 2014: 249).

\section{Santa Fe y la irrupción del virus}

Aquí, nos interesa reflexionar sobre el Covid-19 en la provincia ${ }^{5}$. Con especial atención puesta en el Municipio de Rosario, particularizaremos en la forma en que se vió afectada la salud (no) reproductiva de la ciudadanía usuaria de los efectores públicos de salud. El día número 14 del mes de marzo se conoce el primer caso de coronavirus en la provincia de Santa Fe. Simultáneamente, el flamante Gobernador firma el decreto que da directivas en torno a cumplimentar las medidas que ya habían sido establecidas por el Gobierno Nacional. ${ }^{6}$ 
En los efectores de baja y mediana complejidad, se avanzó en la puesta en marcha del trabajo conjunto en hospitales y centros de salud. Se organizó el ingreso diferenciado para pacientes con síntomas de Covid-19, como también la práctica de distanciar y diferenciar a las pacientes embarazadas y a los niñxs. Se hizo el quiebre entre zonas "limpias" y "de Covid", con recorridos diferenciados y uso de ascensores y escaleras con criterios sanitarios de prevención para el Covid-19 en todos los efectores de salud.

La salud santafesina se organiza en red. Por lo tanto, está conformada por centros de atención provinciales y por espacios dependientes de los municipios. Incluye efectores sin internación -centros de salud, centros de atención ambulatoria, centros de diagnóstico o tratamiento-, y servicios con internación, tales como hospitales con tres niveles de complejidad y redes de soporte para el proceso de atención. En general, en relación con la situación sanitaria de las mujeres, desde el año 2007 se viene trabajando para disminuir las tasas de mortalidad maternoinfantil y para fortalecer los DD.SS. y (no) RR. Santa Fe es una de las provincias que adhirió en el último tiempo a la actualización del protocolo de Interrupción Legal del Embarazo (en adelante ILE). En la capital de esta provincia, se destacan los Hospitales Cullen e Iturraspe, que tienen realidades bastante complejas. Son efectores de segunda complejidad, donde existe una fuerte presencia de equipos de salud que informalmente se declararon objetores de conciencia. Así, en el Hospital Iturraspe, que es un efector público de suma importancia, casi la totalidad de lxs profesionales del servicio de ginecología, en su momento, se declararon públicamente objetores de conciencia. Esta situación se repitió en el Hospital Cullen, donde tampoco se garantiza el acceso a la ILE. Asimismo, es importante destacar que los equipos de salud en estos ámbitos muchas veces son perseguidos y presionados para que no garanticen las interrupciones, con la intención de desarticular esta política pública.

Como señala Vanesa Vásquez Laba, en estos espacios se reproduce el irrespeto a la vida, la salud y la libertad de las mujeres; se disciplina los cuerpos; se judicializan abortos legales; y se incumple el secreto médico, por parte de un Estado descomprometido (2014: 14) En este sentido, se denunció la ausencia de respeto y los cuestionamientos hacia las personas gestantes, en un intento de visibilizar las miradas y posicionamientos corporativos que buscan imponer sus perspectivas por sobre las decisiones de quienes deciden abortar. En el Gran Rosario, por su parte, la situación es distinta. Los equipos de salud, en su mayoría, entienden la ILE como un derecho. Durante la cuarentena obligatoria, en el Municipio de Rosario, la primera recomendación del Área de Salud Sexual Municipal fue evitar quedar embarazadxs y posponer la búsqueda de la maternidad. A lo largo de los primeros meses de la pandemia por Covid-19 no se conocían casos de neonatxs que hubiesen transitado el primer trimestre de gestación con el virus, y no había conocimiento de las consecuencias. En el mismo sentido, las ILE siguieron garantizándose con normalidad, aunque con algunas modificaciones. Se recomendó que las personas que querían acceder a una interrupción legal concurrieran a los centros de salud barriales y no a los hospitales, para evitar un posible contacto con 
infectadxs. Así, se buscó solucionar la mayor cantidad de casos con misoprostol, que permite abortar en la casa, en cumplimiento de la cuarentena.

Por su parte, las ILE elaboradas bajo el método denominado AMEU se focalizaron en dos efectores, el CEMAR y el Roque Sáenz Peña. En relación con los métodos de anticoncepción, se explicó que habría algunas demoras en la llegada al sistema sanitario, aunque la distribución se mantuvo sin alteraciones. A su vez, con respecto a las hormonas para la población travesti-trans, se reconfiguró la forma de distribución, pero no se alteró el acceso. Podemos observar de qué manera un Estado puede entender que existe vida intrauterina y no desprotegerla, aunque ello no implica que sea en detrimento de otros Derechos Humanos, máxime contra los de la mujer gestante, quien es la única a través del cual se va a realizar esa protección (Álvarez, 2014: 91).

En el mismo sentido, desde las organizaciones socorristas Acción Mariposa, Las Nanas Socorristas en red y las Anamaría de Santa Fe, establecieron que se produjo un aumento en las consultas provenientes del norte de la provincia en relación con el acceso al misoprostol. Además, aclaraban que, en los efectores de salud de esa zona de la provincia, el acceso al protocolo de la ILE era dificultoso porque sus responsables se declararon en contra de toda práctica que interrumpiera la reproducción. En consecuencia, en el marco de la pandemia de Covid-19, se multiplicaron las estrategias para garantizar el acceso a la salud (no) reproductiva de las personas por parte de la sociedad civil. Así, las organizaciones feministas, como señala Fraser (2014), en la lucha contra los neoliberalismos ofrecen una y otra vez modelos para resolver la ambivalencia de la igualdad.

\section{Parto respetado en Santa Fe: protocolos y recomendaciones}

La Ley de Parto Respetado implica estar informadx sobre las distintas intervenciones que pudieran tener lugar, y así poder optar ser tratadxs con respeto durante el proceso asistencial, considerando las pautas culturales, además del derecho a que se le otorgue protagonismo en su propio parto. ${ }^{7}$

La cuarentena impuesta por el Gobierno Provincial generó situaciones de vulneración de DD.RR., esto es, se invisibilizó el derecho al parto respetado en algunas instituciones públicas, negando la humanización del embarazo, el parto, y el puerperio. Algunos efectores invisibilizaron la norma sobre el parto con motivo del Covid-19. En particular, prohibieron el libre acceso de unx acompañante durante los días de internación luego del parto. Si bien a nivel nacional e internacional se realizaron las aclaraciones pertinentes con respecto a la reproducción y el respeto a las normativas en relación con los partos y los recaudos que se debían generar en el marco de la pandemia, existieron dificultades a la hora de llevar estas recomendaciones al campo de la práctica. En este sentido, a nivel provincial, se dictaron protocolos de actuación en los que se marcaron algunas regulaciones ante la sospecha o confirmación de coronavirus en las personas gestantes, aunque no justificaban restricciones generales a la Ley de Parto Respetado. ${ }^{8}$ Consecuentemente, para las personas gestantes en situación de parto ciertas cuestiones se modificaron, en particular para las usuarias del sub-sistema público de salud, la 
población más vulnerable de la provincia, a quienes la pandemia volvió sus vidas aún más complejas. El Hospital Iturraspe se caracteriza por no tener afinidad con el cumplimiento de las normativas que resguardan los DD.SS. y RR. Fue señalado como uno de los espacios sanitarios donde se incumplió con la Ley de Parto Respetado, particularmente por no acompañar a la persona gestante en su trabajo de parto, y por dejar a las personas libradas a su suerte en el momento del post-parto junto a lxs recién nacidxs, durante la pandemia. ${ }^{9}$

Más allá de los reclamos de usuarixs del efector y de los equipos de salud que desarrollan sus tareas ahí para lograr el cumplimiento de la Ley de Parto Respetado, la realidad indica que en uno de los Hospitales más importantes de la provincia se violaron los derechos de las personas gestantes por considerar peligroso el ingreso de más personas a la sala de parto en el marco de la pandemia. Las mencionadas salas suelen ser pequeñas, y allí habitualmente se encuentra el personal de pediatría, unx enfermerx, el personal de obstetricia, la persona gestante y la recién nacida. Por lo tanto, la restricción sería una manera de lograr el distanciamiento requerido por las medidas sanitarias. De esta manera, el efector toma las decisiones y precauciones que entiende son las más adecuadas para resguardar la situación sanitaria del espacio, aunque se vulneren derechos. Por otro lado, el Iturraspe posee un comité que evalúa semanalmente las medidas a tomar. En este comité están representadas distintas áreas del hospital, y los debates tienen que ver particularmente con la protección de lxs neonatxs que nacen sanos, y la posición que debe adoptarse en relación con su madre sospechada de infección. También en este marco y en estas líneas, preocupa el lugar en el que se encuentran las personas gestantes dentro del orden de prioridades de la dirección del Hospital y su comité de emergencia. Quienes buscan ejercer sus DD.RR. sufren múltiples violencias en el marco de Covid-19; la que mencionamos es una de ellas, y no la única. Así, en múltiples sentidos, las instituciones estatales tienen comportamientos violentos, como señalan Biglia y San Martín (2007), y se legitima la violencia ejercida por parte del Estado con el pretexto de mantener el orden social. Por eso, es preciso un acercamiento deconstructivo a la forma en la que fue entendido históricamente el término violencia (Biglia y San Martín, 2007: 12).

En el Hospital Cullen, en cambio, sí se busca seguir las recomendaciones señaladas por el Ministerio de Salud Provincial. En este sentido, se busca poder llevar a cabo un parto con respeto, más allá de que en términos de infraestructura no se logra estar al nivel en que se encuentra el nuevo Hospital Iturraspe. El trabajo a realizar requiere redoblar esfuerzos para considerar las libertades reconocidas. Las políticas y prácticas de ciertos efectores santafesinos aquí citados se encuadran en aquello que Fraser (2014) denomina como falta de reconocimiento. Esto implica que a una persona le nieguen la categoría de interlocutor pleno en la interacción social. De este mood, a esa persona se le impide participar como igual en la vida social, no solamente a consecuencia de una inequidad distributiva, sino, por el contrario, como consecuencia de patrones de interpretación y evaluación institucionalizados. Dichos patrones constituyen a la persona como alguien comparativamente indigno o no apto para establecer opiniones al respecto; en este caso, las 
personas gestantes que se ven obligadas a usar el sub-sistema público de salud, por encontrarse en situación de vulnerabilidad.

\section{Reflexiones provisorias}

De las líneas recorridas se vislumbra, en principio, como señaló Maricel Bertolo (2020), que el Aislamiento Social, Preventivo y Obligatorio durante la pandemia producida por el Covid-19 ha profundizado y tornado más visibles las desigualdades económicas y sociales. En especial, patentizó aquellas desigualdades aquellas vinculadas a los sectores menos favorecidos, entre quienes confluyen un conjunto de problemáticas que potencian situaciones de mayor incertidumbre y vulnerabilidad. En este sentido, nos vemos en la imposibilidad de negar la contribución realizada por el capitalismo neoliberal a la rápida expansión del Covid-19 y, en consecuencia, a la profundización de las inequidades que, como suele suceder en el marco de este sistema, perjudican a lxs menos favorecidxs, en este caso las personas que buscan ejercer sus DD.RR.

Es indudable que el surgimiento de la pandemia mostró las debilidades de un sistema sanitario nacional endeble, que se encontraba en emergencia antes de la normativa declarada en el mes de marzo del año 2020. De la misma forma, la contingencia del virus permitió expresar la antipatía hacia algunas libertades conquistadas por los cuerpos gestantes hace ya un tiempo. Así, el Covid-19 vulnera los derechos de aquellas personas que solo pueden recurrir al sub-sistema público.

A modo de cierre, buscamos pensar junto a Nancy Fraser y Linda Gordon (1992: 16), que en un momento de creciente pobreza, desigualdad y fuerte oposición al Estado de Bienestar, hay buenas razones para intentar reconstruir una comprensión de las libertades civiles que promueva la ciudadanía social, en vez de impedirla.

\section{Referencias}

1. Este trabajo se referencia con información presente en la prensa escrita argentina desde el 9 de marzo hasta el día 10 de agosto del año 2020.

2. Se puede observar las recomendaciones del Gobierno Nacional: http://www.msal.gob.ar/images/ $\underline{\text { stories/bes/graficos/0000001839cnt-covid-19-recomendaciones-atencion-embarazadas-recien-naci- }}$ dos.pdf

3. Al respecto, véase: https://diarioz.com.ar/2020/07/29/murio-una-embarazada-en-la-villa-31-noestaba-la-ambulancia-que-larreta-prometio/. Asimismo, véase:

https://www.todojujuy.com/jujuy/libertador-una-mujer-embarazada-y-su-bebe-perdieron-la-vida-covid-n137319

4. Como nota distintiva, es importante marcar que Santa Fe estaba cambiando de color político, en la transición de una gestión direccionada durante 12 años por la coalición socialista-radical (y algo más) Frente Progresista Cívico y Social, a un gobierno de coalición con mayoría peronista.

5. Véase https://www.santafe.gob.ar/ms/covid19/

6. El parto debe ser natural, con respeto por los tiempos biológicos y psicológicos de la persona gestante. De la misma forma, la Ley contempla el derecho de información durante el parto respecto del estado de la persona que va a nacer. La persona gestante no debe ser sometida a estudios para investigaciones, y tiene derecho a tener a su hijx después del parto siempre que la situación lo permita. Asimismo, debe recibir información sobre los beneficios de la lactancia materna, y se le tiene que otorgar información sobre los cuidados de sí misma y del niñx. Información disponible en: https://www.argentina.gob.ar/ 
sites/default/files/ley_25929_parto_humanizado_decreto_web_0.pdf

7. Bajo esta misma línea de análisis, en Santa Fe, se elaboró el documento "Recomendaciones para el manejo de pacientes embarazadas con sospecha o confirmación de infección por Covid-19”. Este documento distingue dos escenarios posibles: embarazada asintomática que regresa de viaje del exterior o tuvo contacto con diagnóstico positivo y embarazada sintomática con sospecha de infección.

8. Información disponible en: https://periodicas.com.ar/2020/05/12/el-hospital-iturraspe-no-cumplela-ley-de-parto-respetado/

\section{Bibliografía}

Álvarez, M. (2014). Estándares en el derecho internacional de los derechos humanos referidos a la persecución penal del aborto. En Deza, S., Iriarte, A. y Alvarez, M., Jaque a la reina. Buenos Aires, Argentina: Cienflores.

Biglia, B. y San Martín, C. (2007). Estado de wonderbra. Entretejiendo narraciones feministas sobre las violencias de género. Barcelona, España: Virus Editorial.

Bertolo, M. (2020). Precariedad e invisibilidad: trabajadoras a domicilio en tiempos de pandemia. En El Ciudadano. Disponible en: https://www.elciudadanoweb.com/suplementos/mundolaboral/926535. html?fbclid=IwAR3T-P5YJyG2KcqC2aKmtCmgXdHIFKyspYm5mtlefUwPglJkD72XHRZ_qSA

Deza, S. (2014). La objeción de conciencia como herramienta de mayorías. En Deza, S., Iriarte, A. y Álvarez, M., Jaque a la reina. Buenos Aires, Argentina: Cienflores.

Fraser, N. (2015). Fortunas del feminismo. Madrid, España: Traficante de sueños.

Fraser, N. y Gordon, L. (1992). Contrato versus caridad: una reconsideración de la relación entre ciudadanía civil y ciudadanía social. NorthWestemUniversity. Recuperado de en http://isegoria.revistas. csic.es/index.php/isegoria/article/view/324.

Ramacciotti, K. (2020). Elogio de lo público. En Caras y Caretas (11/05/2020). Disponible en: https:// carasycaretas.org.ar/2020/05/11/elogio-de-lo-publico/

Vásquez Laba, V. (2014). Prólogo a la primera edición. Injusticia reproductiva. En Deza, S., Iriarte, A. y Álvarez, M., Jaque a la reina. Buenos Aires, Argentina: Cienflores.

Valeria Venticinque, "Pandemia y derechos reproductivos. Respuestas y desventajas". Revista Temas y Debates. ISSN 1666-0714, año 24, número especial, julio-diciembre 2020, pp. 367-374. 